\title{
The flexible fasting technology can improve hypertension: A pilot study in self-controlled designs
}

\author{
Qinghe Ren ${ }^{1,2 \#}$, Wenjing Gong ${ }^{1 \#}$, Rongjie Huang ${ }^{3}$, Lifeng Liang 3 , Kexiang Chen ${ }^{3}$, Dawen Gao ${ }^{1}$, Zhihui Li ${ }^{1}$, Yan Gao ${ }^{1}$, Heliang Liu ${ }^{2}$, \\ Changsheng Chen ${ }^{4 *}$, Jiangnan Huang ${ }^{3 *}$ and Chenggang Zhang ${ }^{1 *}$ \\ ${ }^{1}$ Institute of Radiation Medicine, Academy of Military Medical Sciences, Academy of Military Sciences, Research Center for the Military Cognitive and Mental \\ Health of PLA, Beijing 100850, China \\ ${ }^{2}$ Xijing Hospital of The Fourth Military Medical University, Xi'an 710003, China \\ ${ }^{3}$ The First Affiliated Hospital of Guangxi Medical University, Nanning, Guangxi 530021, China \\ ${ }^{4}$ Department of Health Statistics, School of Military Preventive Medicine, The Fourth Military Medical University, Xi'an 710032, China \\ "Equal contribution.
}

\begin{abstract}
Objective: This study aimed to evaluate the value of the flexible fasting (FF) technology in helping hypertension improvement in patients with essential hypertension and obesity.

Method: We recruited and ultimately selected 86 volunteers with essential hypertension and obesity in this study as a quasi experiment. The volunteers went through three phases, namely, the baseline anti-hypertensive therapy stage (Phase-1), the FF intervention stage (Phase-2), the normal diet recovery stage (Phase-3), each for seven days. During the Phase-2, all subjects fasted and began to substitute the FF food for conventional food. Patients' systolic/diastolic blood pressure (abbreviated as SBP/DBP), body mass index (BMI) and body weight were monitored in details each day. The trial data of all subjects were statistically analyzed using self-controlled designs.
\end{abstract}

Result: After the FF intervention, the subjects' blood pressure, body mass and BMI all showed naturally decreases by comparison to that before the intervention. The remarkable decreases in SBP/DBP, Body Mass and BMI were observed in Phase-3 after FF intervention when compared to Phase-1 [SBP: (115.2 \pm 8.492$)$ vs $(121.2 \pm 13.72) \mathrm{mmHg}, \mathrm{q}=34.14, \mathrm{P}<0.001]$; [DBP: $(76.03 \pm 5.37)$ vs $(78.36 \pm 7.094) \mathrm{mmHg}, \mathrm{q}=10.96, \mathrm{P}<0.05)]$; [Body Mass: $(68.86 \pm 13.04)$ vs $(73.11 \pm 13.49) \mathrm{kg}$, $\mathrm{q}=61.56, \mathrm{P}<0.0001]$; [BMI: $(25.42 \pm 3.359)$ vs $\left.(27.03 \pm 3.45) \mathrm{kg} / \mathrm{m}^{2}, \mathrm{q}=100, \mathrm{P}<0.0001\right]$. All patients did not experience any discomfort or symptoms during the trial.

Conclusion: The FF technology is an effective approach to improve hypertension.

\section{Introduction}

Hypertension is the most common cardiovascular disease (CVD) and a major public health dilemma worldwide. With the rapid growth of China's social and economic level, the prevalence of cardiovascular diseases in China is also continuously raising. Hypertension is one of the most important causes of CVD mortality because of its high prevalence and concomitant vascular risks [1]. This is closely relevant to the improvement of the Chinese public's living standards, changes in diet structure and living habits [2]. Current data demonstrated that Chinese adults with cardiovascular disease had a $30 \%$ mortality rate in 2010 [3].

So far, there are some non-drug treatments for hypertension: improving lifestyle, such as weight loss, salt restriction, reasonable diet, smoking cessation, alcohol restriction, psychological adjustment, applicable exercise, etc. There are treatments of antihypertensive agents, for example, renin angiotensin system aldosterone antagonist medicine (Angiotensin-Converting Enzyme Inhibitors, receptor antagonist, renin antagonists and mineralocorticoid receptor antagonist), diuretics, receptor inhibitors, and calcium channel blockers, etc. [4]. Although these treatments have some therapeutic effects, for most patients, their success rates of the blood pressure control are not satisfactory, and patients' blood pressures do not all meet the recommended level. Therefore, the innovation and progress rate of hypertension treatment methods are still slow, and the growing prevalence of hypertension attaches great importance to the necessity of concentrating on various strategies to hypertension prophylaxis and management [5].

${ }^{\star}$ Correspondence to: Chenggang Zhang, Professor, PhD., Institute of Radiation Medicine, Academy of Military Medical Sciences, Academy of Military Sciences, Research Center for the Military Cognitive and Mental Health of PLA, Beijing 100850, China, Tel: +86 10 66931590; E-mail: zcgweb@126.com

Jiangnan Huang, PhD., The First Affiliated Hospital of Guangxi Medical University, Nanning, Guangxi 530021, China, Tel: +86 771 5356566; E-mail: huangjn1998@163.com

Changsheng Chen, PhD., Department of Health Statistics, School of Military Preventive Medicine, The Fourth Military Medical University, Xi'an 710032, China, Tel: +8629 84774853; E-mail: chencs@fmmu.edu.cn

Key words: hypertension, flexible fasting, body weight control, hunger sensation comes from gut flora, gut flora, gut flora-centric theory, self-controlled designs study, quasi experiment

Received: August 02, 2019; Accepted: September 09, 2019; Published: September 11, 2019 
Overweight and obesity are the main causes of chronic diseases such as essential hypertension [6]. Mohamad-Reza Sedaghat and other scholars have also stated that changes in body mass index (BMI) are significantly correlated with blood pressure, therefore, body weight control will help reduce the incidence of essential hypertension [7]. Reducing energy intake is one of the effective weight control methods, but long-term low energy intakes are inevitable to produce unbearable hunger sensation [8-11].

In our previous studies, we applied the mixture of plant polysaccharides and dietary fiber (named as the flexible fasting (FF) food which containing dietary fiber, Chinese caterpillar fungus polysaccharide, Panax ginseng polysaccharide, Ganoderan polysaccharide, algal polysaccharide, hericiumerinaceus polysaccharide, lyciumbarbarum polysaccharide) to feed the gut flora, and found unexpectedly that the feeling of subjects' hunger sensation was reduced or even naturally disappeared $[12,13]$. According to these issues, we hypothesized that hunger sensation might be caused by the gut flora digesting the gastrointestinal mucosa to obtain the carbon sources as energy for themselves to producing offsprings [14]. The scientific hypothesis that "hunger sensation comes from gut flora" was put forward in recent years [13,15-18]. Based on this hypothesis, we developed the flexible fasting (FF) technology which is different from the traditional fasting method by using the plant polysaccharides and dietary fiber instead of normal food, to help fulfill the process of fasting. We found that those patients who suffered from obesity with essential hypertension also had a decrease in blood pressure after the FF intervention, in addition to their body weight and BMI value. Therefore, this paper designs and illustrates the FF technology in improving the hypertension.

\section{Patients and methods}

\section{Patient eligibility}

This study was conducted and implemented in the Department of Cardiovascular Medicine by the First Affiliated Hospital of Guangxi Medical University. According to the diagnosis of "2010 Chinese hypertension guidelines" [19], 86 patients with essential hypertension were recruited as volunteers to carry out the study on the improvement of hypertension with the FF technology. The subjects ranged in age from 19 to 67, including 34 males and 52 females. All subjects took antihypertensive agent regularly and their blood pressure was stable. The volunteers' BMI ranged from 19.66 to $33.74 \mathrm{~kg} / \mathrm{m}^{2}$. In accordance with the world health organization (WHO) revised BMI standards for Chinese adults, 68 overweight individuals in this study accounted for $79 \%$ of the total number of subjects [20].

The main exclusion criteria were: Systolic Blood Pressure (SBP) >185 mmHg; taking >2 antihypertensive agents; secondary hypertension and hypotension of any etiology; postural hypotension; severe cardiopulmonary, liver, kidney and/or other important organ dysfunction; severe cerebrovascular disease; severe osteoarthrosis such as fracture; other diseases that affect diet and exercise; mental illness; the volunteers were pregnant or nursing.

\section{Protocol of the one-week flexible fasting (FF) technology}

The one-week FF technology is a special low-calorie dietary culture, in which normal diet at per meal was replaced by prebiotics formula (energy level: $113.4 \mathrm{KJ} / 10 \mathrm{~g}$ ), without any nutriment, all-embracing the five cereals (rice, two kinds of millet, wheat and beans) and other food containing protein or fat for one-week. During the one-week FF, their routine activities including working, resting kept normal habit.

\section{Study design}

This was a 3-week phase, open-label study to evaluate the effect of FF technology in subjects with essential hypertension. The study was launched from Jun 2016 and Dec 2016 and included the baseline anti-hypertensive therapy stage (Phase-1), the FF intervention stage (Phase-2), the normal diet recovery stage (Phase-3). Each of these phases persisted in one week. A total of 86 eligible subjects were enrolled in the self-controlled design study. The study was approved by the institutional review board or ethics committees and was conducted according to the Declaration of Helsinki and Good Clinical Practice guidelines. All subjects gave written informed consent to participate in the study. The trial allowed all volunteers to withdraw from the trial at any time for any reason. Finally, 86 subjects completed the study successfully.

The subjects continued to receive the original baseline antihypertensive therapy in the course of the Phase-1 before the intervention of FF for one week to maintain stable blood pressure. In the second stage, the FF stage (Phase-2), the volunteers used the FF food to replace normal diet for a week. The method of consumption of the FF food is $10 \mathrm{~g}$ per meal, 3-4 meals per day, mixed with warm water and taken orally directly. As the SBP was observed to be lower than $110 \mathrm{mmHg}$ sometimes during the phase- 2 of FF intervention, we suggested the use of anti-hypertensive drugs should be reduced or discontinued, and the stability of blood pressure should be intently monitored. It is important to ensure adequate water intake during the intervention stage, and a daily amount of 3000 to $5000 \mathrm{ml}$ were recommended. At the end of FF administration, subjects resumed a normal or light diet, and the semiliquid diet is suggested during the first part of this period to adapt to the recovery of gastrointestinal digestive function, and afterward gradually return to a light or routine diet. Body weight was assessed by weighingmachine in the morning. In addition, blood pressure data measured with sphygmomanometer between $6 \sim 10$ o'clock and 16 20 o'clock were recorded as the key records.

Either a standard mercury sphygmomanometer or a certified automated and calibrated blood pressure device was used, as well as appropriate cuff size. In case the auscultation method was used, SBP and DBP were measured at Korotkoff Phase I and V, respectively. Every effort was made to standardize the conditions of clinic BP monitoring [21]. The trial data of all subjects was statistically analyzed using selfcontrolled designs as a quasi experiment.

\section{Endpoints}

The primary outcome was differences in systolic and diastolic mean $\mathrm{BP}$ values, and differences in body weight and BMI. Safety was evaluated by recording any adverse events, notably: drowsiness, dizziness, nausea, headache, weakness and/or rash.

\section{Statistical analysis}

Statistical analysis was performed using commercially available software (SPSS Version 20.0). Data are expressed as means \pm standard deviation. The data of body weight, BMI, SBP, DBP at different time of points of each phase were analyzed by multifactor analysis of variance (Two-way ANOVA). Provided that it was statistically significant, the SNK-q test was used for comparisons between each of groups. The level of statistical significance (P-value) was set at 95\% $(\alpha=0.05)$. P $>0.05$ was considered as statistically insignificant. $\mathrm{P}<0.05\left({ }^{*}\right), \mathrm{P}<0.01\left(^{* *}\right)$, $\mathrm{P}<0.001\left(^{(* *)}, \quad \mathrm{P}<0.0001\left(^{* * *}\right)\right.$ respectively take into account as statistically different. 


\section{Results}

\section{Efficacy and safety}

The mental tension of some subjects was shown at the beginning of the FF trial, and thereafter the subject discomfort gradually disappeared after the subjects got used to the trial form. None of the volunteers experienced sleepiness, dizziness, nausea, headache, general tiredness and/or rash during the three stages of the study. Finally, all 86 volunteers with hypertension and obesity achieved the FF technology trial to reduce blood pressure, body mass and BMI.

\section{Trends of body weight}

The subjects' body weight was relatively stable during the first seven days of the study. Subsequently, the diurnal decline in body weight became apparent after the onset of the FF intervention. The slight upward trend of the curve was seen within seven days after the resumption of diet, as shown in Figure 1.

After the completion of the trial, we compared the body weight values of each phase and made a statistical analysis. It was found that the mean body weight was decreased significantly after the FF intervention stage, as shown in Figure 2.

The remarkable decrease in body weight after FF was significantly larger in Phase- 2 than in Phase- 1 ( $\mathrm{q}=39.73, \mathrm{P}<0.0001)$, was significantly larger in Phase-3 than in Phase-1 ( $\mathrm{q}=61.56, \mathrm{P}<0.0001)$, and was significantly larger in Phase- 3 than in Phase-2 ( $\mathrm{q}=21.83, \mathrm{P}<0.0001)$, as shown in Table 1.

\section{Trends of body mass index (BMI)}

As shown in Figure 3, the BMI curve shows decline in the FF stage and slight increase in the normal diet recovery stage day-to-day. The results of mean BMI data analysis of 86 volunteers were summarized, and it was found that BMI was decreased significantly after the intervention of FF technology, as shown in Figure 4.

The mean BMI value in Phase-2 was significantly lower than that in Phase-1 ( $\mathrm{q}=65.07, \mathrm{P}<0.0001)$, and that in Phase- 3 was significantly lower than that in Phase-1 $(\mathrm{q}=100, \mathrm{P}<0.0001)$, and that in Phase-3 was significantly lower than that in Phase- $2(q=34.97, P<0.0001)$. The differences between these stages were statistically significant, as shown in Table 1.

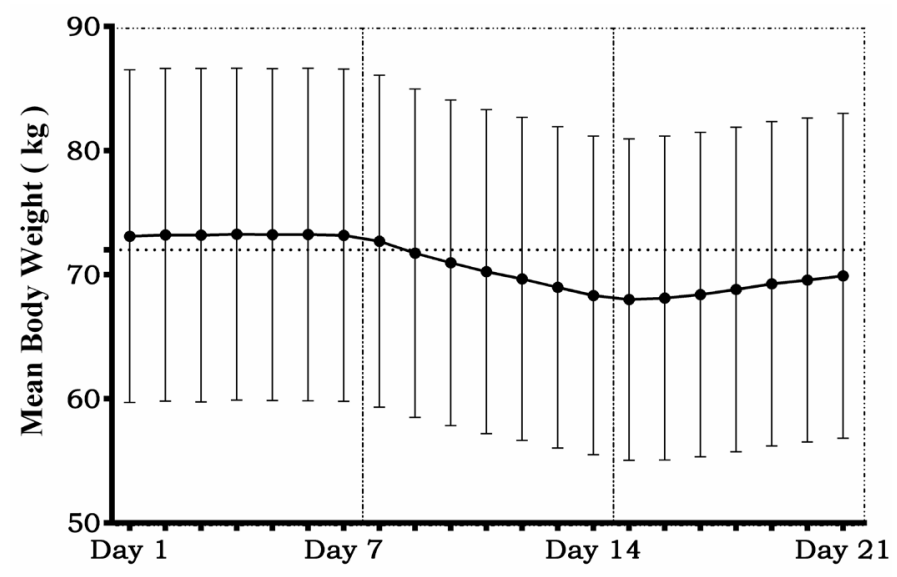

Figure 1. Diurnal change in body weight
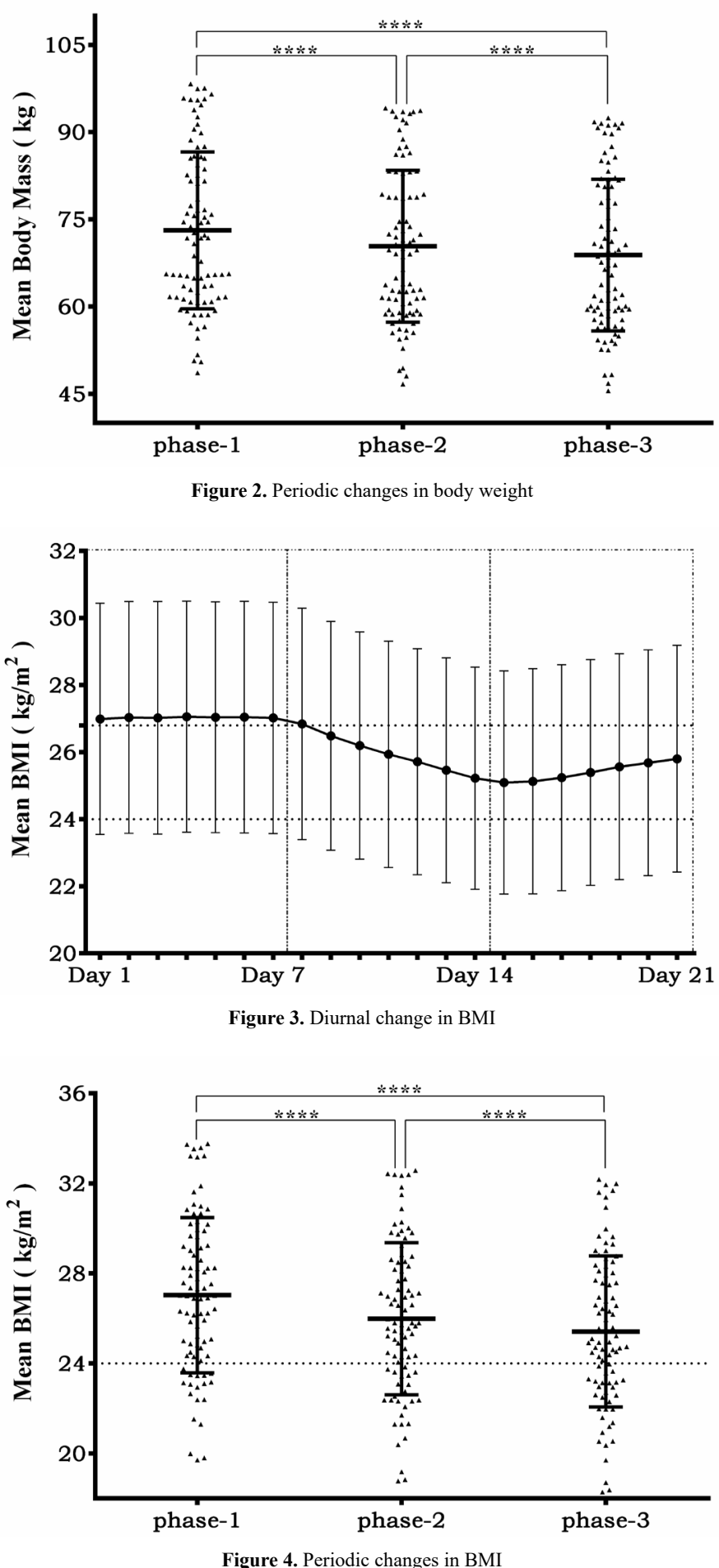

Trends of SBP/DBP in ante meridiem

In order to avoid the effect of physiological blood pressure fluctuation in the morning and evening on the test results, the blood pressure values were measured at 6 10 o'clock and 16 20 o'clock respectively in this study.

The systolic/diastolic blood pressure records in ante meridiem are shown in Figure 5. It can be observed that the SBP/DBP decreased day by day from the beginning of the FF technology intervention, and that 
Table 1. Outcomes of pairwise comparison of data in three phases of the flexible fasting technology trial

\begin{tabular}{|c|c|c|c|c|c|c|c|c|c|c|}
\hline \multirow[t]{2}{*}{ Variables } & \multicolumn{3}{|c|}{ Phase comparison } & \multirow[t]{2}{*}{$\mathbf{N}$} & \multicolumn{3}{|c|}{ q value } & \multicolumn{3}{|c|}{ p value } \\
\hline & Phase-1 & Phase-2 & Phase-3 & & $\begin{array}{l}\text { Phase: } \\
1 \text { vs } 2\end{array}$ & $\begin{array}{l}\text { Phase: } \\
1 \text { vs } 3\end{array}$ & $\begin{array}{l}\text { Phase: } \\
2 \text { vs } 3\end{array}$ & $\begin{array}{l}\text { Phase: } \\
1 \text { vs } 2\end{array}$ & $\begin{array}{l}\text { Phase: } \\
1 \text { vs } 3\end{array}$ & $\begin{array}{l}\text { Phase: } \\
2 \text { vs } 3\end{array}$ \\
\hline Body Mass,kg & $73.11 \pm 13.49$ & $70.37 \pm 13.07$ & $68.86 \pm 13.04$ & 86 & 39.73 & 61.56 & 21.83 & $\mathrm{P}<0.0001$ & $\mathrm{P}<0.0001$ & $\mathrm{P}<0.0001$ \\
\hline BMI, $\mathrm{kg} / \mathrm{m}^{2}$ & $27.03 \pm 3.45$ & $25.98 \pm 3.376$ & $25.42 \pm 3.359$ & 86 & 65.07 & 100 & 34.97 & $\mathrm{P}<0.0001$ & $\mathrm{P}<0.0001$ & $\mathrm{P}<0.0001$ \\
\hline $\begin{array}{l}\text { SBP-AM, } \\
\text { mmHg }\end{array}$ & $121.3 \pm 13.93$ & $116.7 \pm 10.02$ & $115.3 \pm 8.425$ & 86 & 7.137 & 9.297 & 2.16 & $\mathrm{P}<0.001$ & $\mathrm{P}<0.0001$ & $\mathrm{P}>0.05$ \\
\hline $\begin{array}{l}\text { DBP-AM, } \\
\text { mmHg }\end{array}$ & $78.06 \pm 7.991$ & $76.58 \pm 6.184$ & $76.29 \pm 5.309$ & 86 & 4.896 & 5.831 & 0.9354 & $\mathrm{P}<0.01$ & $\mathrm{P}<0.001$ & $\mathrm{P}>0.05$ \\
\hline $\begin{array}{l}\text { SBP-PM, } \\
\text { mmHg }\end{array}$ & $121.1 \pm 13.72$ & $116.2 \pm 10.48$ & $115 \pm 8.954$ & 86 & 19.71 & 24.58 & 4.868 & $\mathrm{P}<0.0001$ & $\mathrm{P}<0.0001$ & $\mathrm{P}<0.01$ \\
\hline $\begin{array}{c}\text { DBP-PM, } \\
\text { mmHg }\end{array}$ & $78.66 \pm 7.076$ & $75.39 \pm 6.526$ & $75.77 \pm 5.935$ & 86 & 11.39 & 10.04 & 1.351 & $\mathrm{P}<0.0001$ & $\mathrm{P}<0.0001$ & $\mathrm{P}>0.05$ \\
\hline $\begin{array}{l}\text { SBP-All Day, } \\
\text { mmHg }\end{array}$ & $121.2 \pm 13.72$ & $116.5 \pm 10.12$ & $115.2 \pm 8.492$ & 86 & 26.8 & 34.14 & 7.344 & $\mathrm{P}<0.0001$ & $\mathrm{P}<0.0001$ & $\mathrm{P}<0.0001$ \\
\hline $\begin{array}{l}\text { DBP-All Day, } \\
\text { mmHg }\end{array}$ & $78.36 \pm 7.094$ & $75.98 \pm 5.834$ & $76.03 \pm 5.37$ & 86 & 11.2 & 10.96 & 0.2461 & $\mathrm{P}<0.0001$ & $\mathrm{P}<0.0001$ & $\mathrm{P}>0.05$ \\
\hline
\end{tabular}

N: Number; Phase-1: The baseline anti-hypertensive therapy stage; Phase-2: The flexible fasting intervention stage; Phase-3: The normal diet recovery stage; BMI: Body mass index; SBP-AM: Systolic blood pressure in ante meridiem; DBP-AM: Diastolic blood pressure in ante meridiem; SBP-PM: Systolic blood pressure in post meridiem; DBP-PM: Diastolic blood pressure in post meridiem; SBP-All Day: All-Day systolic blood pressure; DBP-All Day: All-Day diastolic blood pressure

a slight upward curve of the SBP/DBP after the normal diet recovery stage was observed.

After the mean SBP-AM data of each stage were compared in pairs, it was found that there was a significant difference in the decrease of the SBP-AM after the FF intervention, as shown in Figure 6. In each phase pair, SBP-AM was significantly lower than Phase-1 in Phase-2 ( $\mathrm{q}=7.137, \mathrm{P}<0.001$ ), and was significantly lower than Phase- 1 in Phase-3 ( $\mathrm{q}=9.297, \mathrm{P}<0.0001)$, but was insignificantly lower than Phase- 2 in Phase-3 ( $\mathrm{q}=2.16, \mathrm{P}>0.05)$, as shown in Table 1 .

According to the mean DBP-AM data shown in Figure 7, the decreasing trend of DBP was apparent after the intervention of FF technology. In each phase pair, the DBP-AM in Phase- 2 is significantly lower than that of Phase-1 $(\mathrm{q}=4.896, \mathrm{P}<0.01)$, and in Phase- 3 is significantly lower than that in Phase- $1(\mathrm{q}=5.831, \mathrm{P}<0.001)$, while in Phase-3 is insignificantly lower than that of Phase-2 ( $\mathrm{q}=0.9354$, $\mathrm{P}>0.05$ ), as shown in Table 1 .

\section{Trends of SBP/DBP in post meridiem}

At the same time, it was also observed in Figure 8 that SBP-PM and DBP-PM decreased significantly day by day during the FF intervention stage and was maintained a stable state in the course of the normal diet recovery stage.

The mean SBP-PM value showed a decreasing trend stage by stage, and the statistical analysis indicated that the SBP-PM decreased significantly after the FF intervention, as shown in Figure 9. The SBP$\mathrm{PM}$ in Phase-2 was significantly lower than that in Phase-1(q=19.71, $\mathrm{P}<0.0001)$, while in Phase- 3 was significantly lower than that in Phase$1(\mathrm{q}=24.58, \mathrm{P}<0.0001)$, and in Phase- 3 was significantly lower than that in Phase-2 $(\mathrm{q}=4.868, \mathrm{P}<0.01)$, as shown in Table 1.

After the mean DBP-PM data of each stage was compared in couples, it was found that there was a significant difference in the decrease of the DBP-PM after the FF intervention, as shown in Figure 10. Additionally, the DBP-PM in Phase-2 has obvious decline relative to the phase- 1 ( $\mathrm{q}=11.39, \mathrm{P}<0.0001)$, while in phase- 3 relative to the phase- 1 is significantly downward $(\mathrm{q}=10.04, \mathrm{P}<0.0001)$, but in phase -3 relative to the phase-2 has no statistical differences $(\mathrm{q}=1.351, \mathrm{P}>0.05)$, as shown in Table 1.
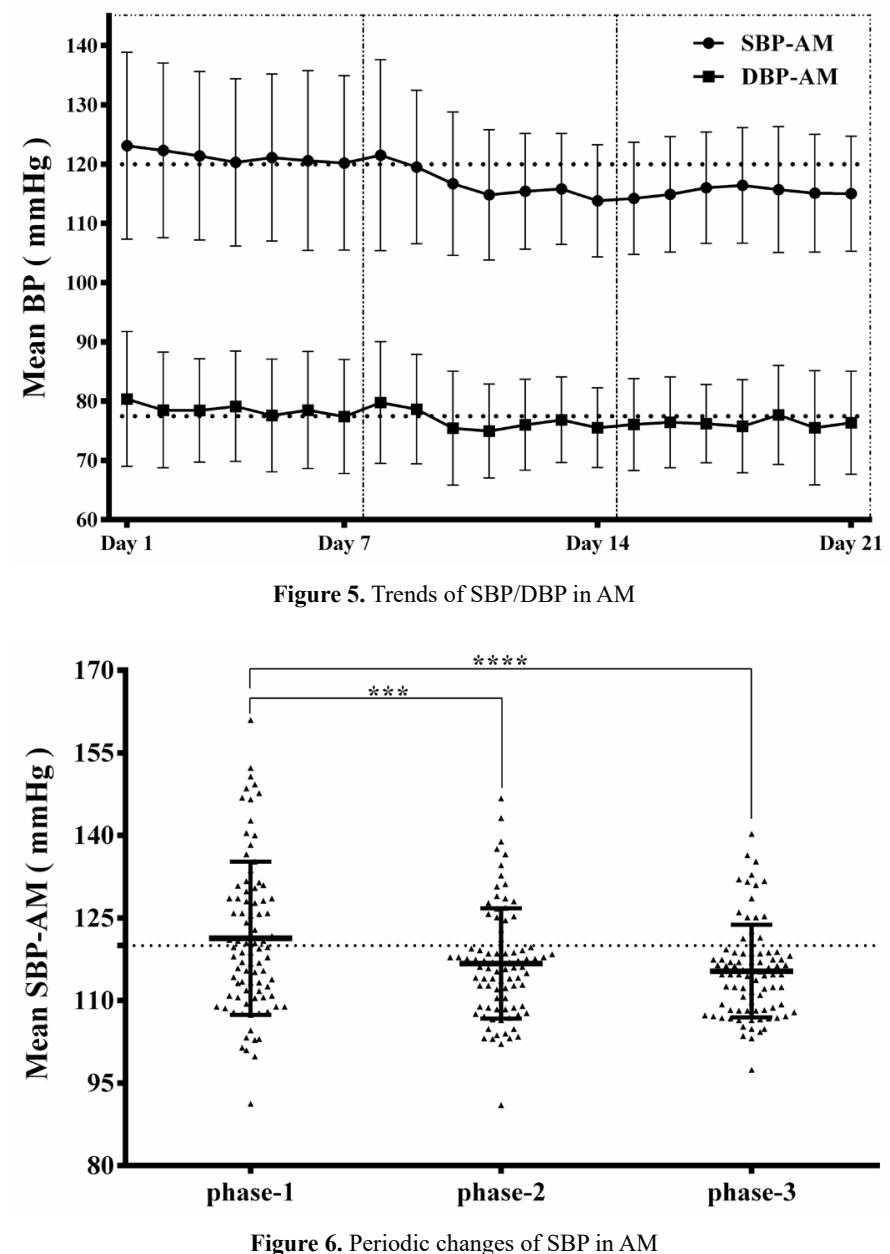

\section{Trends of all-day SBP/DBP}

The changes of SBP-AM, DBP-AM, SBP-PM and DBP-PM were summarized to obtain the mean all-day SBP and DBP data. The SBPAll Day and DBP-All Day decreased significantly during the week of FF intervention, while was maintained during the week of diet restoration, as shown in Figure 11. 

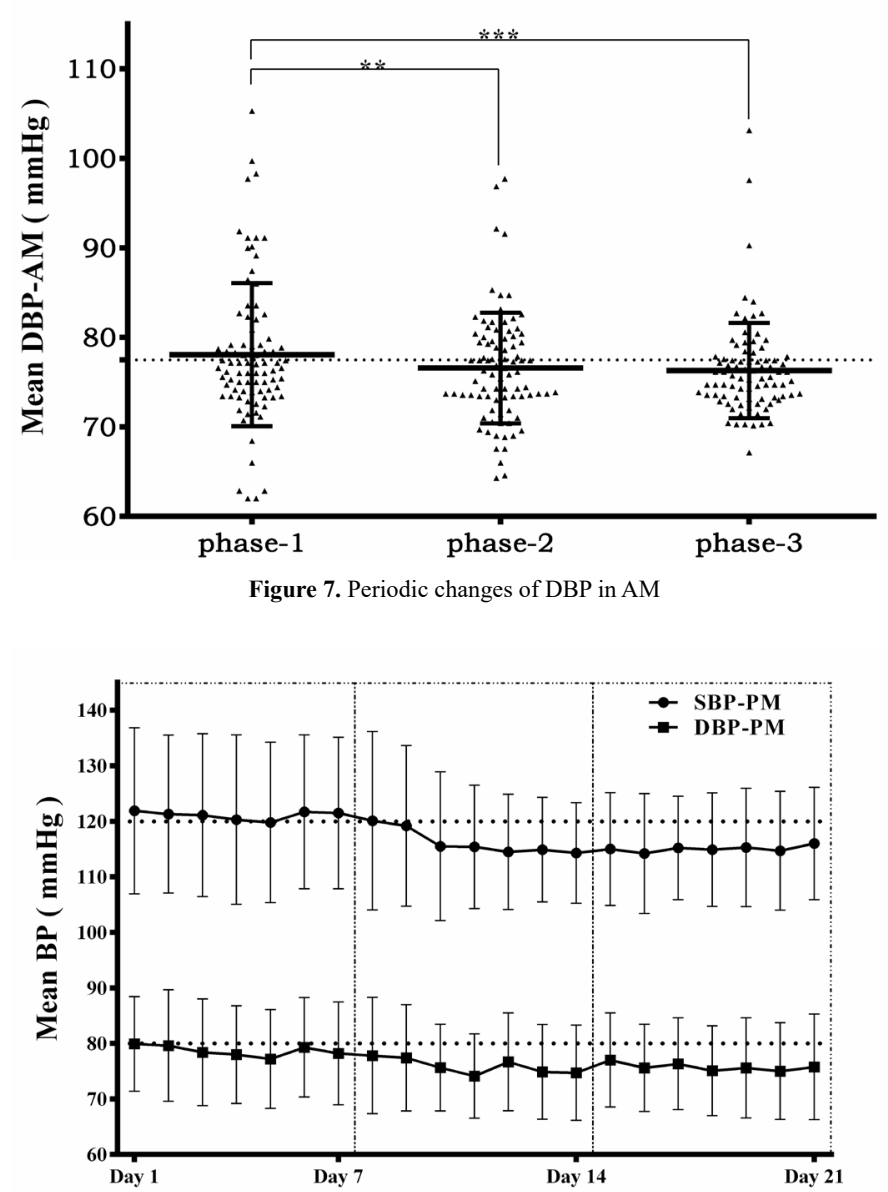

Figure 8. Trends of SBP/DBP in PM

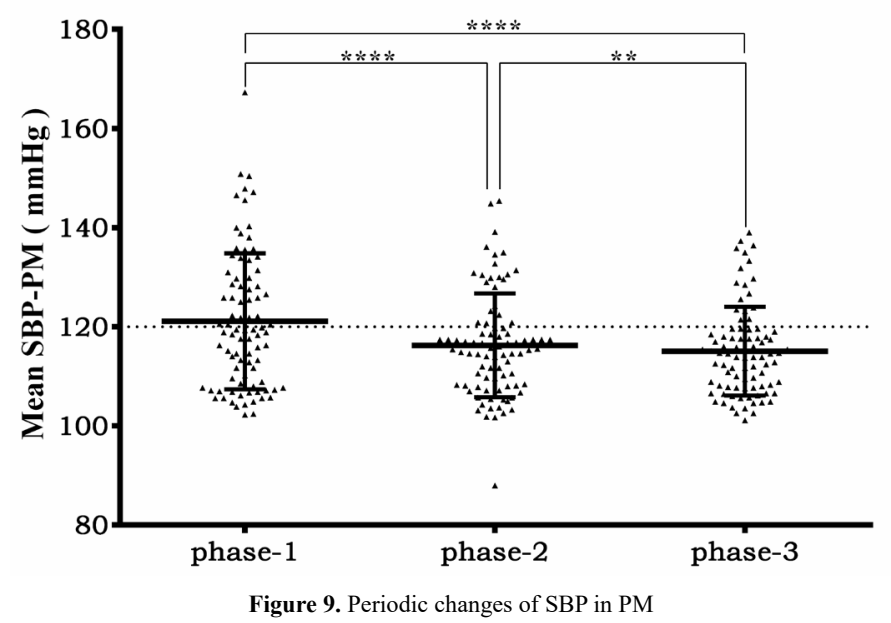

According to the mean SBP-All Day data shown in Figure 12, the decreasing trend of that was apparent after the intervention of $\mathrm{FF}$ technology. The SBP-All Day in Phase- 2 has obvious decline relative to the Phase-1 ( $\mathrm{q}=26.8, \mathrm{P}<0.0001)$, and in Phase-3 relative to the Phase-1 has significant decline $(\mathrm{q}=34.14, \mathrm{P}<0.0001)$, while in Phase- 3 relative to the Phase- 2 also has a significant difference ( $\mathrm{q}=7.344, \mathrm{P}<0.0001)$, as shown in Table 1.
The mean DBP-All Day value showed a decreasing trend by stages, and the statistical analysis illustrated that the DBP-All Day decreased significantly after the FF intervention stage, as shown in Figure 13. The DBP-All Day in Phase-2 was significantly lower than that in Phase-1 ( $\mathrm{q}=11.2, \mathrm{P}<0.0001)$, while in Phase- 3 was significantly lower than that in Phase-1 ( $\mathrm{q}=10.96, \mathrm{P}<0.0001)$, but in Phase- 3 is insignificantly lower than that in Phase-2 ( $\mathrm{q}=0.2461, \mathrm{P}>0.05)$, as shown in Table 1 .

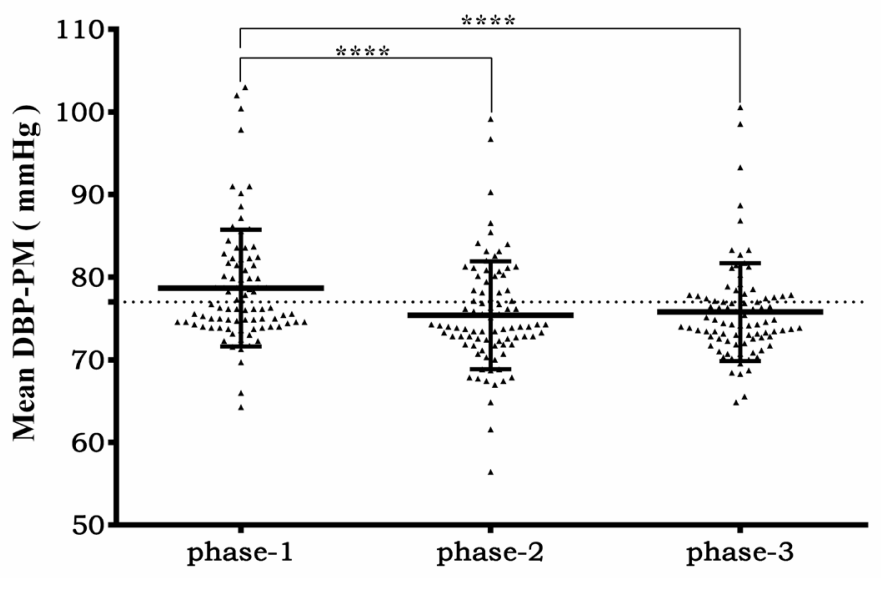

Figure 10. Periodic changes of DBP in PM

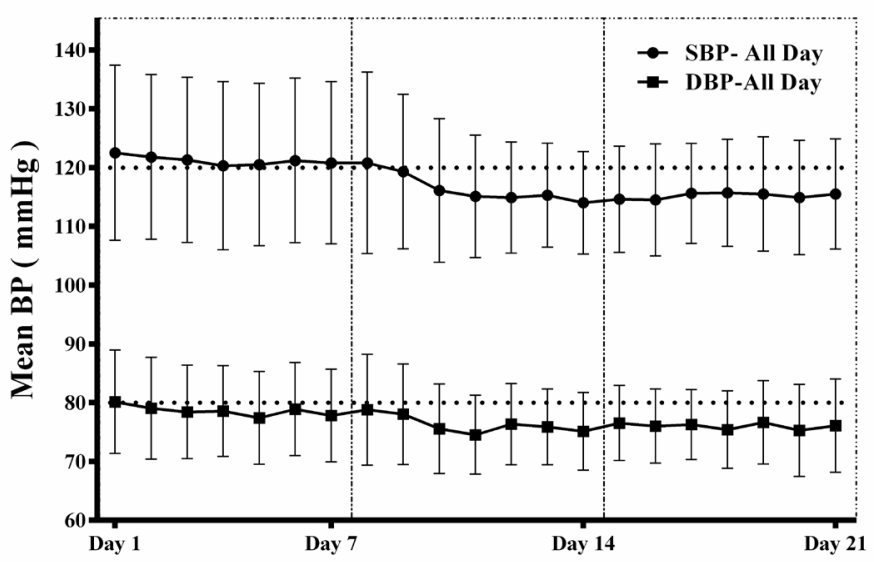

Figure 11. Trends of SBP/DBP in all day

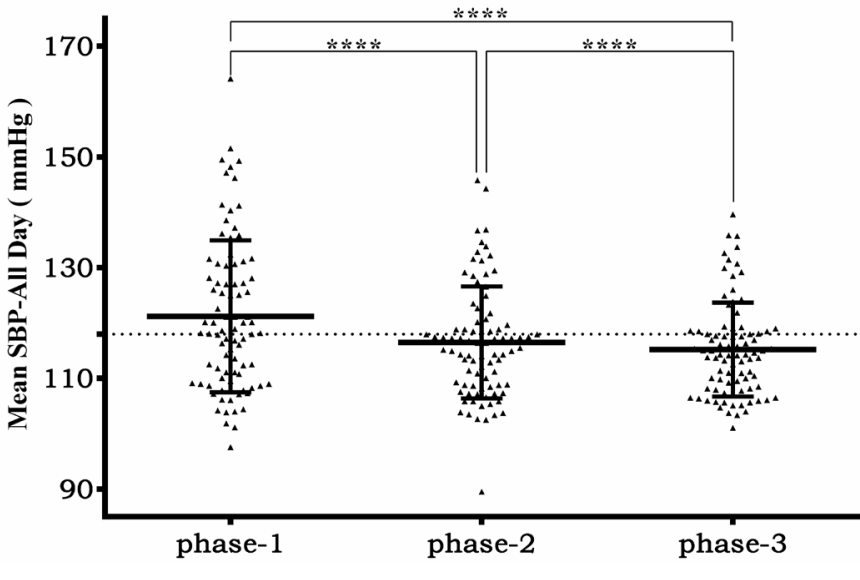

Figure 12. Periodic changes of SBP in all day 


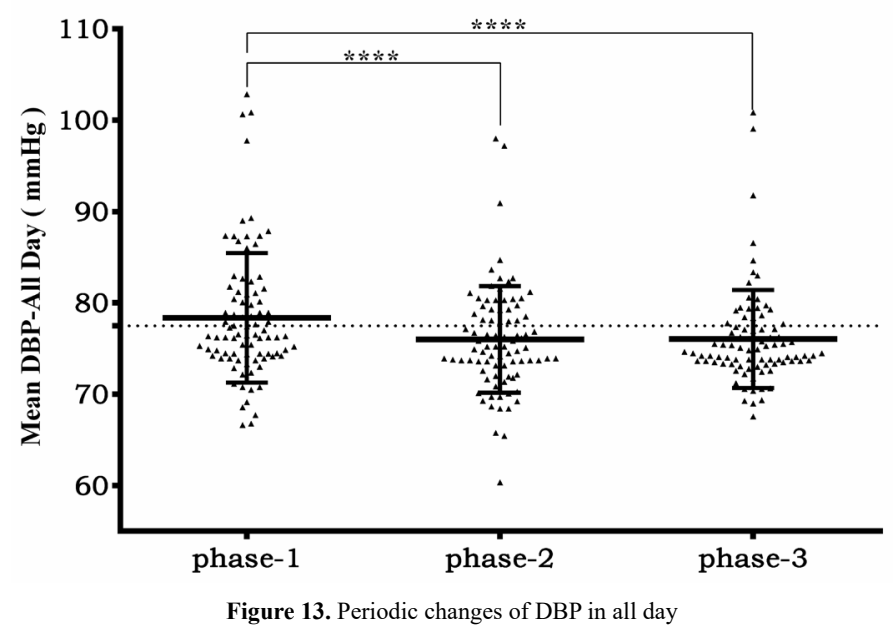

\section{Discussion}

It is an indisputable fact that the prevalence of essential hypertension has increased rapidly in China. Today's health care system has to develop a set of relatively mature diagnosis and treatment of essential hypertension, but sometimes it is inconvenient in clinical application, since the patients must either adhere to lifelong medication, or put to use a combination of several antihypertensive agents, and the majority of the patient's level of blood pressure was not fully under control and is accompanied by an array of hypertension complication [22]. As a matter of fact, the treatment of essential hypertension is not optimistic. At present, the medical community has begun to cultivate the healthy lifestyle to assist anti-hypertensive drug treatment as a breakthrough point to improve the current situation $[23,24]$. Some researchers believed that the body weight is closely relevant to patients' blood pressure levels, and advocate the use of weight loss, dietary fiber and other ways to intervene in chronic diseases such as hypertension and diabetes [25-27]. Therefore, one of the most critical and common ways to improve the lifestyle is calorie restriction.

It is well known that the trational Chinese style of fasting, named bigu, is a classic method of calorie restriction with Chinese Taoist characteristics [28]. Bigu, which was literally interpreted as avoiding grains or abstaining from five cereals in the Encyclopedia of China, is a Taoist fasting technique developed in context of Taoist philosophy and has been used in ancient China to seek longevity and even immortality [29-31]. Over the past century caloric restriction in international basic medical researches fully confirmed that calorie restriction can be effective anti-aging and treatment of various chronic diseases, but the clinical application is extremely insufficient because of the strong hunger dilemma in the process of caloric restriction [32]. To address this issue, the FF technology introduced in this paper has solved this bottleneck. Naturally, in this study, we used the FF food to control patients' blood pressure levels, using FF technique and the results were consistent with expectations. Obviously, the basis of the study is the unexpected discovery that use of the FF food can significantly alleviate or even eliminate the hunger sensation, which in turn provide direct evidences that the hunger sensation might come from gut flora.

The SBP, DBP, body mass, and BMI of all subjects in this study were significantly reduced after a week of FF intervention. When a week after resuming normal light diet, both body weight and BMI were lower than those before intervention, and systolic/diastolic blood pressure remained low. This suggests that if the subjects continued to maintain a good lifestyle after the FF intervention, their blood pressure, weight and BMI would probably remain normal. Some scholars also believe that the decrease of body weight, waist circumference and BMI can also influence the significant decrease of systolic/diastolic blood pressure $[7,20]$, which is consistent with the results of this study. In this study, the body weight and BMI were significantly decreased during the FF phase, which was caused by the decomposition and consumption of fat reserves. Dietary fiber and plant-based polysaccharide in the FF food can reduce the intake of salt, increase the discharge of $\mathrm{Na}^{+}$, inhibit the rise of blood pressure, and finally lead to a significant decrease in SBP/ DBP level of volunteers [33-35].

At present, quite a few scholars claim that the risk factors of essential hypertension are highly correlated with the imbalance of gastrointestinal flora, which is likely to be the environmental factors of hypertension [36-39]. Therefore, we may be able to understand the mechanism of FF technology to reduce blood pressure through the recovery of intestinal flora disorder. The identification of plant polysaccharide as a regulator of gut microbiota has received more and more approvals [40-42]. According to previous studies in our laboratory, the FF food mainly composed of plant polysaccharide that has beneficial evident effect on gut microbiota $[43,44]$. Therefore it is reasonable to conclude that when we use the FF technology to improve hypertension environmental factors to adjust and optimize the gastrointestinal flora, we can achieve indirectly the decrease in the level of blood pressure of hypertension patients.

\section{Perspective}

Because of the gut flora dysbiosis in patients with essential hypertension reported in the academia should be identifed based on the $16 \mathrm{~S}$ rDNA sequencing with bioinformatics analysis, further works should be focused on the relationship between chronic diseases and gastrointestinal flora disorder to bridge the gap between the the status of gut flora and the human health [37,38,45-48].

\section{Conclusion}

In this study, patients with essential hypertension, who were in the baseline anti-hypertensive treatment, adopted a novel way to help them to conquer the disease, finally their SBP/DBP levels, body weight and BMI were controlled reasonably after the intervention of FF. This may revolutionize non-drug interventions for essential hypertension from an unconventional perspective. Although there was a small recovery in body weight and BMI in course of the resume period of normal or light diet, but not in SBP/DBP, which indicates that in order to maintain the stability of blood pressure and other indicators, it is highly recommended for us to continue to use a healthy lifestyle.

In addition, during the trial all participants did not experience discomfort such as dizziness, nausea, etc., indicating the FF technology can be used as a kind of safe and effective blood pressure control method for clinical adjuvant therapy. Taken together, the FF technology might provide an alternative choice for prevention and control scheme of hypertension and other obesity-related chronic diseases, which is also of great significance to the international public health.

\section{Disclosures}

The flexible fasting food mentioned in this paper was provided by the Beijing Cloud Medicine International Technique Co., LTD. The publication of this paper does not conflict with the interests of 
the company or others. This study only provides suggestions for the treatment of hypertension, not commercial publicity.

\section{Sources of funding}

This work was supported by grants of China's national major new drug creation program: 2012ZX09102301-016 and 2014ZX09J1410705B, and the general program No. 81573251 of the Natural Science Foundation of China to the Institute of Radiation Medicine, Academy of Military Medical Sciences.

\section{References}

1. Kearney PM, Whelton M, Reynolds K, Muntner P, Whelton PK, et al. (2005) Global burden of hypertension: analysis of worldwide data. Lancet 365: 217-223. [Crossref]

2. Wu X, Duan X, Gu D, Hao J, Tao S, et al. (1995) Prevalence of hypertension and its trends in Chinese populations. Int J Cardiol 52: 39-44. [Crossref]

3. Lewington S, Lacey B, Clarke R, Guo Y, Kong XL, et al. (2016) The burden of hypertension and associated risk for cardiovascular mortality in China. JAMA Intern Med 176: 524-532. [Crossref]

4. Sharma PL, Pandhi P (1985) Progress in the treatment of essential hypertension. Int $J$ Clin Pharmacol Ther Toxicol 23 Suppl 1: S54-61. [Crossref]

5. Paulis L, Unger T (2010) Novel therapeutic targets for hypertension. Nat Rev Cardiol 7: 431-441. [Crossref]

6. Chen C, Lu FC, Department of disease control ministry of health, PR China (2004) The guidelines for prevention and control of overweight and obesity in Chinese adults. Biomed Environ Sci 17 Suppl: 1-36. [Crossref]

7. Sedaghat MR, Askarizadeh F, Nematy M, Narooie-Noori F, Heravian J, et al. (2017) The relationship of body mass index and blood pressure with corneal biomechanical parameters in healthy subjects. Med Hypothesis Discov Innov Ophthalmol 6: 89-97. [Crossref]

8. Wadden TA, Stunkard A J, Brownell K (1983) Very low calorie diets: their efficacy, safety, and future. Annals of Internal Medicine 9: 675-684.

9. Lappalainen R, Sjödén PO, Hursti T, Vesa V (1990) Hunger/craving responses and reactivity to food stimuli during fasting and dieting. International Journal of Obesity 14: 679-688.

10. Johnstone AM, Faber P, Gibney ER, Elia M, Horgan G, et al. (2002) Effect of an acute fast on energy compensation and feeding behaviour in lean men and women. Int J Obes Relat Metab Disord 26: 1623-1628.

11. Johnstone A (2005) Fasting for weight loss: an effective strategy or latest dieting trend? International Journal of Obesity 39: 727-733.

12. Gong WJ, Huang QJ, Gao DW, et al. (2016) Application of flexible abrosia for body weight control among youths. Mil Med Sci 40: 651-656.

13. Huang QJ, Teng SZ, Gao DW, et al. (2015) Emergency plans of flexible abrosia to raise efficiency in disaster rescue. Disaster Medicine and Rescue 4: 81-85.

14. Zhang CG (2018) The Gut Flora-Centric Theory Based on the New Medical Hypothesis of "Hunger Sensation Comes from Gut Flora": A New Model for Understanding the Etiology of Chronic Diseases in Human Beings. Austin Intern Med 3: 1030-1036.

15. Gao DW, Gong WJ, Li ZH, et al. (2018) Effect of standardized comprehensive nutrition intervention on pregnancy outcome of pregnant women with gestational diabetes mellitus. Food and Nutrition in China 24: 76-79.

16. Su YS, Xu YY, Lu YM, Fang HP, Gao DW, et al. (2017) Preliminary study on the effect of flexible abrosia on chronic urticaria. E-Journal of Translational Medicine 4: 20-25.

17. Ren QH, Huang JN, Huang RH, et al. (2017) Preliminary Study on Flexible Abrosia Technology to Improve Hypertension. Food and Nutrition in China 23: 70-75.

18. Zhang CG, Gong WJ (2017) Discovery based on hunger sensation comes from gut flora: Breakthrough in chronic disease prevention and control. Sci Technol Rev 2017: 43-48.

19. Liu LS, Writing group of 2010 chinese guidelines for the management of hypertension (2011) 2010 Chinese guidelines for the management of hypertension. Zhonghua Xin Xue Guan Bing Za Zhi 39: 579-615. [Crossref]

20. Ouyang Y, Wang H, Su C, Wang Z, Song Y, et al. (2015) Use of quantile regression to investigate changes in the body mass index distribution of Chinese adults aged 18-60 years: a longitudinal study. BMC Public Health 15: 278. [Crossref]
21. Pickering TG, Hall JE, Appel LJ, Falkner BE, Graves J, et al. (2005) Recommendations for blood pressure measurement in humans and experimental animals: part 1: blood pressure measurement in humans: a statement for professionals from the Subcommittee of Professional and Public Education of the American Heart Association Council on High Blood Pressure Research. Circulation 111: 697-716. [Crossref]

22. Pietinen P, Huttunen JK (1989) [Prevention of blood pressure diseases and non-drug management]. Duodecim 105: 1402-1409. [Crossref]

23. Walford RL, Harris SB, Gunion MW (1992) The calorically restricted low-fat nutrientdense diet in Biosphere 2 significantly lowers blood glucose, total leukocyte count, cholesterol, and blood pressure in humans. Proc Natl Acad Sci U S A 89: 11533-11537.

24. Herrod P, Doleman B, Blackwell J, O'Boyle F, Williams JP, et al. (2018) Exercise and other nonpharmacological strategies to reduce blood pressure in older adults: a systematic review and meta-analysis. J Am Soc Hypertens 12: 248-267. [Crossref]

25. Rahmouni K, Correia ML, Haynes WG, Mark AL (2005) Obesity-associated hypertension: new insights into mechanisms. Hypertension 45: 9-14. [Crossref]

26. Washburn RA, Szabo AN, Lambourne K, Willis EA, Ptomey LT, et al. (2014) Does the method of weight loss effect long-term changes in weight, body composition or chronic disease risk factors in overweight or obese adults? A systematic review. PLoS One 9: e109849. [Crossref]

27. Aleixandre A, Miguel M (2016) Dietary fiber and blood pressure control. Food Funct 7: 1864-1871. [Crossref]

28. Chu WZ, Xu F, Wang YY (2006) Research the influence of PiGuShiEr therapy on biochemical metabolism in experical mice. Hebei Journal of Traditional Chinese Medicine 28: 139-141.

29. Wang J, Jin J, Xue X, Hao Y, Li D, et al. (2017) An unusual case of perforation of the alimentary canal following Bigu: A Taoist fasting technique. Medicine (Baltimore) 96: e8653. [Crossref]

30. Editorial Board of Encyclopedia of China. Traditional Chinese Medicine Volume [M] Beijing, China: Encyclopedia of China Publishing House, 1992.

31. Li DX (2012) Brief discussion on Bigu method in Taoist medicine. China Journal of Traditional Chinese Medicine and Pharmacy 27: 1230-1232.

32. Wang XQ (2017) An analysis of traditional Bigu health and caloric restriction. Clinical Journal of Chinese Medicine 9: 45-47.

33. Charrondiere UR, Chevassus-Agnes S, Marroni S, Burlingame B (2004) Impact of different macronutrient definitions and energy conversion factors on energy supply estimations. Journal of Food Composition and Analysis 17: 339-360.

34. Whelton SP, Hyre AD, Pedersen B, Yi Y, Whelton PK, et al. (2005) Effect of dietary fiber intake on blood pressure: a meta-analysis of randomized, controlled clinical trials. J Hypertens 23: 475-481. [Crossref]

35. Mahboobi S, Iraj B, Maghsoudi Z, Feizi A, Ghiasvand R, et al. (2014) The effects of probiotic supplementation on markers of blood lipids, and blood pressure in patients with prediabetes: a randomized clinical trial. Int J Prev Med 5: 1239-1246. [Crossref]

36. Mell B, Jala VR, Mathew AV, Byun J, Waghulde H, et al. (2015) Evidence for a link between gut microbiota and hypertension in the Dahl rat. Physiol Genomics 47: 187197. [Crossref]

37. Yang T, Santisteban MM, Rodriguez V, Li E, Ahmari N, et al. (2015) Gut dysbiosis is linked to hypertension. Hypertension 65: 1331-1340. [Crossref]

38. Jose PA, Raj D (2015) Gut microbiota in hypertension. Curr Opin Nephrol Hypertens 24: 403-409. [Crossref]

39. Delzenne NM, Neyrinck AM, Cani PD (2011) Modulation of the gut microbiota by nutrients with prebiotic properties: consequences for host health in the context of obesity and metabolic syndrome. Microb Cell Fact 2011:S10.

40. Wang M, Chen Y, Wang Y, Li Y, Zheng H, et al. (2018) The effect of probiotics and polysaccharides on the gut microbiota composition and function of weaned rats. Food Funct 9: 1864-1877. [Crossref]

41. Matsuki T, Yahagi K, Mori H, Matsumoto H, Hara T, et al. (2016) A key genetic factor for fucosyllactose utilization affects infant gut microbiota development. Nat Commun 7: 11939. [Crossref]

42. Xu J, Lian F, Zhao L, Zhao Y, Chen X, et al. (2015) Structural modulation of gut microbiota during alleviation of type 2 diabetes with a Chinese herbal formula. ISME J9: 552-562.

43. Gong W, Sun C, Teng S, Gao W, Li Z, et al. (2018) Evaluation of a novel fasting approach using plant polysaccharides per meal in human symbionts. Int Clin Med. 2: 1-12 
44. Yu Z (2016) The mechanism research on anti-aging effects of specific probiotics in caenorhabditis elegans [D]. Guangxi Medical University.

45. Zhang CG (2015) New medicine and bacteriocentric theory and a revolution in prevention and control of chronic diseases. Sci Technol Rev 33: 106-111.

46. Zhang CG, Gong WJ (2018) Flexible bigu: a new approach for improving obesity and related chronic diseases. Medical Journal of Chinese People's Health 30: 100-102.
47. Zhang CG, Gong WJ, Li ZH, Gao D, Gao Y (2019) Research progress of gut flora in improving human wellness. food science and human wellness. Food Science and Human Wellness 8: 102-105.

48. Zhang CG, Gong WJ, Li ZH, Gao D, Gao Y (2019) A biological hypothesis: is it possible that human symbiotic microbiota coding hunger genes for human beings? Journal of Advances in Health 1: 145-148.

Copyright: (C2019 Ren Q. This is an open-access article distributed under the terms of the Creative Commons Attribution License, which permits unrestricted use, distribution, and reproduction in any medium, provided the original author and source are credited. 